\title{
Designing the voices
}

\author{
Yoram Reich
}

Published online: 8 January 2011

(c) Springer-Verlag London Limited 2011

As we start a new volume of RED at the brink of a new year, the question "where are we headed" is always worthwhile to ask. As an editor, coming up with insight to share with readers, or as a researcher, generating interesting research topics that will entice the community, is challenging. Innovating continuously, is a tough task for us researchers, as it is for engineering design professionals whom we study and for whom we seek to provide support.

How, therefore, do we answer that question?

Let us seek guidance in the practice of professional designers. Let us consider the ways they attempt to achieve relevance, value, and innovation for their customers. Let us consider the initial stages of a development project when the "killer" idea is sought. What might be the sources of such ideas?

The literature documents diverse sources for innovative product ideas:

1. Voice of the customer is a classic source of product ideas and preferences (Akao 1990). Listening to customers who are owners of the product or prospective buyers improves the chances that the product indeed addresses real needs and desires.

2. Voice of the users elevates the role of users to become innovators (Von Hippel 2005). As the direct beneficiaries of innovation, users make use of new platforms to participate in the innovation process and share their insight with other users.

3. Voice of the crowd could be another source of insight in what might be perceived as mega-brainstorming (Surowiecki 2004). It is argued that in order to

Y. Reich $(\bowtie)$

Tel Aviv University, Tel Aviv, Israel

e-mail: yoram@eng.tau.ac.il succeed, the crowd has to be diverse and decentralized, opinions have to be independent of each other and they should be summarized into one potential collective answer. This begins to remind us of a recent debate in the journal arising, among other things, from interpretations of Arrow's impossibility theorem (Reich 2010).

4. Voice of the competitors is also a classic source of information. Studying competitors to anticipate where they are heading together with the voice of the customer and the engineers is part of the popular House of Quality method (Akao 1990).

5. Voice of the product is a less familiar source of information but one that could lead to creative product ideas by studying the product attributes and their dependencies (Goldenberg and Mazursky 1999).

We are seeing a trend to mobilize the masses for insight, to democratize innovation (von Hippel 2005). For Research in Engineering Design, the aforementioned sources provide valuable information for shaping the journal. We consider customers but mainly users to be readers, authors, and reviewers whose feedback regarding the review process or the published material is extremely valuable. The "crowd" is not yet a utilized source, perhaps for the lack of a suitable platform available to us to engage a large community. Nevertheless, there is a permanent call for input from the community at large to partake in shaping RED. A platform for other stakeholder participation is being planned as well. Competing journals and the journal itself as a product are also sources of ideas and sometimes inspiration. I constantly look at other design related journals and the way they are managed to gain new ideas. Such competition leads to differentiating RED from the other journals by promoting fundamental issues that have intellectual and practical impact. 
But in spite of the trend to engage the masses, there is a documented exception with far reaching consequences that needs attention. Instead of relying on users, social networks, virtual communities, or on many ideas that are generated quickly and screened down to few successful; an opposite approach has evolved which one could call listening to the voice of interpreters, but is better phrased as design-driven innovation (Verganti 2009). I will refer to it as:

6. Designing the voices mentioned above. Instead of mere listening to voices, designers collaborate with a selected group of interpreters who are able to understand and project the meaning that people give or will give to products. With these interpreters, designers can come up with products that create new meanings for people. They actually require stepping back from present conceptions and designing new grounds.

If we want to innovate by discovering new promising research areas, be creative in running the journal or in its focus, we need to pay attention to this source of insight as well. For RED, the interpreters are the members of the advisory board. These are seasoned researchers with major experience in different design areas, leading to different perspectives and interpretations of what design means. Their task is to look around and propose to us where we might find challenging and critical fundamental issues and how might we address them in a way that would influence engineering design practice in the near or far future. It is therefore, my pleasure to present the current members of the Advisory Board:

1. Prof. Takahiro Fujimoto

Professor, Faculty of Economics, The University of Tokyo, Japan

Executive Director, Manufacturing Management Research Center

Senior Research Associate, Harvard Business School

2. Prof. Eswaran Subrahmanian

Chief Scientist, CSTEP, Bangalore, India

Research Professor, Institute of Complex Engineered

Systems, Carnegie Mellon University, USA (on leave)

Visiting Honorary Professor, International Institute of Information Technology, Bangalore, India

3. Prof. Nam P. Suh

Ralph E. \& Eloise F. Cross Professor, Massachusetts Institute of Technology, Cambridge, USA

President, Korea Advanced Institute of Science and Technology, Seoul, South Korea

4. Prof. Roberto Verganti

Professor, School of Management, Politecnico di Milano, Italy

Visiting Professor, Copenhagen Business School, Denmark

Adjunct Professor, University of Vaasa, Finland
While presenting the Advisory Board of RED, I would like to mention another 'interpreter' or visionary, Prof. Kenneth Preiss, who passed away on October 26th 2010. For 20 years, since the founding of RED, he was an editorial board member of the journal. An obituary of him is included in this issue.

\section{Reviewers' appreciation}

The beginning of a new issue marks the ending of 2010 and it is time to thank all the reviewers who contributed their precious time to review papers and provide valuable comments. This effort maintains and improves the high quality of the journal.

The following are the reviewers who served the journal in 2010:

Ade Mabogunje

Albert Albers

Alison McKay

Aminul Islam

Andy Dong

Armin Shmilovici

Arnaud De Grave

Asko Riitahuhta

Aydin Nassehi

Belinda Lopez-Mesa

C. K. Kwong

Carolyn Rose

Carolyn C. Seepersad

Catherine Barnes

Charles Eastman

Chris Earl

Chris Paredis

Christian Hicks

Christian Weber

Christopher McMahon

Clark Cory

Claudia Eckert

Claus Hansen

Dan Frey

Daniel Whitney

David Kazmer

David Blockley

David Ben-Arieh

David Wynn

Deborah Thurston

Donna Rhodes

Erik Antonsson

Ernst Fricke

Filippo Salustri

Gül E. Okudan Kremer

Gary Wang 
George Huang

Georges Fadel

Giovanna Vianello

Greg Mocko

Gui-jiang Duan

Hernan Casakin

Harald Schaub

Harrison Kim

Herbert Birkhofer

Imre Horvath

Ingrid Utne

Ioannis Fudos

Irem Tumer

James Moultrie

Jan Treur

Jan Schoormans

Janet McDonnell

Janet Allen

Jianxin Roger Jiao

Jiao Jiangxin

Jitesh Panchal

Johan Malmqvist

John Gershenson

Jonathan Cagan

Jose Molina

Katja Hölttä-Otto

Kemper Lewis

Kevin Caskey

Kristina Lauche

Linden J Ball

Li-Pheng Khoo

Maik Maurer

Margaret Wiecek

Maria Yang

Marin Guenov

Martin Stacey

Masuru Nakano

Matt Giess

Matthew Campbell

Maya Kaner

Michael Pasqual

Michael Scott

Mohamed Zied Ouertani

Nathan Crilly

Nitin Joglekar

Norbert Roozenburg

Offer Shai

Oliver de Weck

P. John Clarkson

Paul Hekkert

Pedro Company

Peter Matthews

Peter Heisig
Qi Van Eikema Hommes

Rafael Sacks

Raymond Holt

Richard Storch

Richard Malak Jr.

Richard Crowder

Rick Schifferstein

Rivka Oxman

Robert Stone

Roland De Guio

Roman Zavbi

Ruben Perez

$S$ Vinodh

Saeema Ahmed-Kristensen

Shun Takai

Snelders Dirk

Steve Culley

Stig Ottosson

Stuart Burgess

Teresa Wu

Terry Bahill

Tijen Ertay

Tommy Tucker

Toshiharu Taura

Turkka Keinonen

Tushar Goel

Udo Lindemann

Vesna Popovic

Warren Seering

Weiyin Ma

WF Lu

Xun Xu

Yakov Ben-Haim

Yaneer Bar-Yam

Yih Tng Chong

Yong Zeng

Yuh-Min Chen

Yves Keraron

\section{References}

Akao Y (ed) (1990) Quality function deployment. Integrating customer requirements into product design. Productivity Press, Cambridge

Goldenberg J, Mazursky D (1999) The voice of the product: templates of new product emergence. Innov Creat Manag 8(3):157-164

Reich Y (2010) Editorial, my method is better!. Res Eng Des 21(3):137-142

Surowiecki J (2004) The wisdom of crowds: why the many are smarter than the few and how collective wisdom shapes business, economies, societies and nations. Doubleday, New york

Verganti R (2009) Design driven innovation - changing the rules of competition by radically innovating what things mean. Harvard Business Press, Boston

Von Hippel E (2005) Democratizing innovation. MIT Press, Cambridge 